EGU2020-10100

https://doi.org/10.5194/egusphere-egu2020-10100

EGU General Assembly 2020

(c) Author(s) 2020. This work is distributed under

the Creative Commons Attribution 4.0 License.

\title{
Cumulative impact of small reservoirs : a review of estimations and methods
}

\author{
Florence Habets ${ }^{2}$, Jérôme Molénat ${ }^{1}$, Nadia Carluer ${ }^{3}$, Olivier Douez ${ }^{4}$, and Delphine Leenhardt ${ }^{5}$ \\ ${ }^{1}$ LISAH, Univ. Montpellier, INRAE, IRD, SupAgro, Montpellier, France \\ ${ }^{2}$ ENS, Laboratoire de géologie, CNRS,Paris, France \\ ${ }^{3}$ INRAE, UR RiverLy, F-69625, Villeurbanne, Lyon-France \\ ${ }^{4}$ BRGM, Bordeaux, France \\ ${ }^{5}$ AGIR, INRAE, INPT, Toulouse, France
}

Due to a reduce cost, availability of many favorable locations, easy access due to proximity, the number of small reservoirs has increased, especially in arid and semi-arid regions. The cumulative impact of reservoirs in a catchment is considered as the modifications induced by the reservoir network taken as a whole. The impact may exert on the flow regimes and sediment, nutrient and contaminant transfer, and thereby modify the ecological behaviour of the aquatic environment, the continuity of rivers and the habitats of organisms living in them. The cumulative impact is not necessarily the sum of individual and local modifications, because reservoirs may be interdependent. This is the case for instance in cascading reservoirs along a stream course. The cumulative impact is not straightforward to estimate, even solely considering hydrological impact, in part due to the difficulty to collect data on the functioning of those reservoirs. However, there are evidences that the cumulative impacts are not negligible.

This work is dedicated to a review of the studies dealing with the cumulative impact of small reservoirs on hydrology, focusing on the methodology as well as on the way the impacts are reported. It is shown that similar densities of small reservoirs can lead to different impacts on the quantitative water resource in different regions. This is probably due to the hydro-climatic conditions, and makes it difficult to define simple indicators to provide a first guess of the cumulative impact. The impacts vary also on time, with a more intense reduction of the river discharge during the dry years than during the wet years. This is certainly an important point to take into account in a context of climate change.

Habets, F., Molénat, J., Carluer, N., Douez, O. and Leenhardt,D, 2018, The cumulative impacts of small reservoirs on hydrology: A review, Science of The Total Environment, 643, 850-867, doi.org/10.1016/j.scitotenv.2018.06.188 